\title{
Elderly Welfare and Quality of Life: A qualitative inquiry
}

\author{
Rugayah Hashim¹, Zaidi Mohd Aminuddin², Ayu Rohaidah Ghazali2, Norfadzilah Abd Razak² \\ ${ }^{1}$ Research \& Innovation Unit, ${ }^{2}$ Faculty of Business \& Management, \\ Universiti Teknologi MARA Cawangan Selangor, Puncak Alam, Selangor, Malaysia
}

guy73106@yahoo.com, pmzaid@yahoo.com.my, ayurohaidah@gmail.com, norfadzilah0438@gmail.com Tel: +6013-3852288

\begin{abstract}
As the elderly population increases in Malaysia, media-reported spates on elderly abuse and neglect formed the motivation for the study. The objectives of this paper are to showcase the findings on elderly welfare and neglect via two-phase, qualitative design inquiry. The findings revealed that homecared elderly parents reported a steady quality of life with isolated incidences of neglect. Culture, tradition, and religion play essential roles in elderly care and emotional well-being. Implications from the study evidenced the importance of elderly welfare for societal inclusion and quality of life. Gazetting new policies on elderly welfare are recommended.
\end{abstract}

Keywords: Elderly welfare; Geriatrics; Neglect; Elderly Abuse

eISSN: 2398-4287 @ 2019. The Authors. Published for AMER ABRA cE-Bs by e-International Publishing House, Ltd., UK. This is an open access article under the CC BYNC-ND license (http://creativecommons.org/licenses/by-nc-nd/4.0/). Peer-review under responsibility of AMER (Association of Malaysian Environment-Behaviour Researchers), ABRA (Association of Behavioural Researchers on Asians) and cE-Bs (Centre for Environment-Behaviour Studies), Faculty of Architecture, Planning \& Surveying, Universiti Teknologi MARA, Malaysia.

DOI: https://doi.org/10.21834/e-bpj.v4i12.1748

\subsection{Introduction}

As reported by the World Health Organization (Organization, 2018), the proportion of the world's population over the age of 60 years will increase from $12 \%$ to $22 \%$ by 2050 . With a faster pace of the population aging, all countries will face significant challenges in ensuring that their health and social systems are ready for this demographic shift. Moreover, by $202080 \%$ of older people will come from developing and less developed countries (Organization, 2018). Similarly, the elderly population in Asia is projected to grow by more than $35 \%$ as the baby boomers become senior citizens (ADB, 2017). In tandem with this situation, the pertinent stakeholders focusing on elderly welfare and geriatrics must be prepared for this reality. In doing so, the cases on elderly abuse and neglect have been highlighted from media coverage and literature search. This means that the issue is on the rise globally. As such, the sharing of findings from this paper comes at the right time for policymakers and government agencies to be prepared for the geriatric issue.

\subsection{Literature Review}

\subsection{Malaysia's aging population}

For Malaysia, the life expectancy of the population has averaged 73-75 years taking the nation's elderly (65+ years) segment at a respectable $6.7 \%$ in 2019 from $6.5 \%$ in 2018 (Statistics-Malaysia, 2019). With a current population of 32.5 million, the number will further increase after 2020. With the aged population making up a significant percentage of the overall population, the socio-economic aspects of the country will need to adapt to this change. Much of this percentage are educated baby boomers with specific lifestyles that showed an extended life expectancy with females having a longer life (Mafauzy, 2000).

eISSN: 2398-4287 ( ) 2019. The Authors. Published for AMER ABRA cE-Bs by e-International Publishing House, Ltd., UK. This is an open access article under the CC BYNC-ND license (http://creativecommons.org/licenses/by-nc-nd/4.0/). Peer-review under responsibility of AMER (Association of Malaysian Environment-Behaviour Researchers), ABRA (Association of Behavioural Researchers on Asians) and cE-Bs (Centre for Environment-Behaviour Studies), Faculty of Architecture, Planning \& Surveying, Universiti Teknologi MARA, Malaysia. DOI: https://doi.org/10.21834/e-bpj.v4i12.1748 
In Asian culture, it is the norm to care for elderly parents and other close relatives. Therefore, the quality of life experienced at home is considered ideal. However, in today's rat race, is it?

\subsection{The Elderly Welfare}

Research projects on geriatrics have become a primary agenda throughout the world as baby boomers formed a significant percentage of the elderly population. The literature on research projects involving geriatrics, palliative, and the elderly have provided a multitude of scopes for further investigations. Nonetheless, the focus on elderly welfare has been emphasized lately, particularly on abuse - neglect and maltreatment. As pointed by Decalmer and Glendenning (1993), neglect and abuse of older people are not new. Several attempts have been made to find out the reasons for the abuse. In the United States, Canada, and Britain, between $91-95 \%$ of the elderly live in the communities while the rest in institutional settings (ibid). There is "chilling evidence that these elderly people are more like to be at risk" of abuse at the institutions. On the other hand, the vast majority of older people are cared for at home, but there is evidence that a considerable amount of violence taking place within the family setting (ibid). With this in mind, the current scenario has shown similar abuse of the elderly in Asia (Abdi, Tarjoman, \& Borji, 2019; ADB, 2017).

\subsection{Elderly Care}

Aging past the golden years will see a reduction in individual human faculties. As opined by Daskalopoulou et al. (2019), older people will lose their mental and physical capacities. Some societies will marginalize and look at them with contempt (ibid). Those who have strong mental abilities will come to accept this low evaluation of themselves and learn to be helpless. As reiterated by Daskalopoulou et al. (2019) and Decalmer and Glendenning (1993), "when people are considered to be of little value to society, there will be less restraint on treating them with abuse and neglect." Back to the crux of the matter, elderly care for those in Asian countries remains the priority for the immediate family members. This is part of filial piety (Cheng \& Cheng, 2015). Nevertheless, the importance of raising the profile of the elderly care cannot be over-emphasized, but in today's Information Era, education alone does not provide the panacea for proper elderly care; changes in social attitudes are required (Decalmer \& Glendenning, 1993; Dickerson, Lindner, Scurich, \& Quas, 2017).

On the other side of the spectrum, elderly care in old folks home, for example, have indicated a prevalence of ageist attitudes and inherent in such attitudes is the denigration of older people (Davies, 1993) in (Decalmer \& Glendenning, 1993). Moreover, the way that older people are perceived can be an essential indicator of caregiving (ibid). Caring for the elderly requires patience. Family members would know and understand the eccentricities of elderly parents. Therefore, having their parents staying in the same household may produce challenges in they are mentally incapable such as dementia (Helton, Boutwell, \& DiBernardo, 2017). The costs for elderly care are also another issue that the family members must accommodate. Different cultures and races may have their way of showing filial piety, but the result is ensuring that proper care is accorded to the elderly parents.

\subsection{Elderly Abuse and Neglect}

On the other side of the coin, caring for the aging population involved numerous responsibilities discharged by various stakeholders. More often than not, the elderly were reportedly abused and neglected (Decalmer \& Glendenning, 1993; Friedman, Avila, Rizvi, Partida, \& Friedman, 2017). In defining elder abuse and neglect, Glendenning (1993) stated that there were many explanations of these two terms, but what remains is the perceptions from different perspectives of the victim, the caregiver, the physician, the nurse, the agency, the social worker, and social policy. However, Eastman (1984 in Glendenning, 1993) defined old age abuse as the 'systematic maltreatment of an elderly person by a care-giving relative. This may take the form of physical assault, threatening behavior, neglect, and abandonment or sexual assault'. Elder abuse falls under the typology of domestic abuse, but a specific distinction remains. The abuse can be classified into (ibid):

-physical abuse - being hit, sexually assaulted, burned or physically restrained,

-psychological abuse - the elderly are being insulted, frightened, humiliated, intimidated or treated like a child

-medical abuse - involved the withholding of or careless administration of drugs,

-social and environmental abuse - including the deprivation of human services, and involuntary isolation and financial abuse,

-material abuse - including misuse of property or money, theft, forced entry into a nursing home, financial dependence, and exploitation.

For elder neglect, there is passive and active neglect (ibid). Passive neglect occurs when an older person is being left alone, isolated, or forgotten. Active neglect involved the withholding of items that were necessary for daily living (such as food, medicine, companionship, bathing), the withholding of life resources, and not providing care for the physically dependent person (ibid). These two definitions provided the bases for the research undertaking. Also, the regular news highlights on parental abuse, especially, have caught the attention of the specific ministry where priority is needed to ensure that the victims are protected. As previously mentioned, Malaysia's mainstream newspapers (Table 1) have regularly reported parental and elderly abuse. Some have resulted in fatalities.

Table 1. Media reports of parent and elderly abuse

\begin{tabular}{|l|l|l|}
\hline \multicolumn{1}{|c|}{ Media highlights } & Media name \& year & \multicolumn{1}{c|}{ Comments } \\
\hline Looking after our elderly & The Star, 2019 & $\begin{array}{l}\text { One in 10 elderly also reported experiencing abuse } \\
\text { at the hands of someone known to them in the past } \\
12 \text { months }\end{array}$ \\
\hline
\end{tabular}




\begin{tabular}{|c|c|c|}
\hline $\begin{array}{l}\text { Stan Lee's ex-manager charged } \\
\text { with elder abuse of comic book co- } \\
\text { creator }\end{array}$ & $\begin{array}{l}\text { Reuters in The Star, } \\
2019\end{array}$ & $\begin{array}{l}\text { Ex-manager was charged with five counts of elder } \\
\text { abuse stemming from an incident when Lee was } 95 \\
\text { years old }\end{array}$ \\
\hline $\begin{array}{l}\text { Malaysia is getting old fast, but are } \\
\text { we ready for an elderly nation? }\end{array}$ & $\begin{array}{l}\text { The Star Online, } \\
2019\end{array}$ & $\begin{array}{l}\text { According to a Universiti Malaya survey conducted } \\
\text { in } 2014 \text {, one in } 10 \text { seniors is abused in urban areas, } \\
\text { while the figure is one in } 20 \text { in rural areas. } \\
\text { Family members may not necessarily live together, } \\
\text { but all forms of abuse happen, e.g., neglect, } \\
\text { physical, emotional, psychological, and financial. }\end{array}$ \\
\hline $\begin{array}{l}\text { It is Chinese New Year, but elder } \\
\text { abuse means some Malaysians } \\
\text { are alone and neglected }\end{array}$ & $\begin{array}{l}\text { The Star Online, } \\
2019\end{array}$ & $\begin{array}{l}\text { Experts claim elder abuse and neglect is prevalent } \\
\text { not just in Malaysia, but everywhere else }\end{array}$ \\
\hline Finally, an Act for the elderly & $\begin{array}{l}\text { The Star Online, } \\
2019\end{array}$ & $\begin{array}{l}\text { By } 2020 \text {, children who neglect, abandon or abuse } \\
\text { their elderly parents could be penalized by the law, } \\
\text { once Parliament passes legislation to safeguard the } \\
\text { rights of the elderly }\end{array}$ \\
\hline $\begin{array}{l}\text { Spending time with our elderly can } \\
\text { extend their lives and enrich ours }\end{array}$ & $\begin{array}{l}\text { The Star Online, } \\
2019\end{array}$ & $\begin{array}{l}\text { The Peace study in } 2016 \text { found an alarmingly high } \\
\text { incidence of abuse among the elderly in Malaysia. } \\
\text { One of the forms of abuse is neglect. The study } \\
\text { also found a link between abuse and shorter life } \\
\text { spans in its respondents. }\end{array}$ \\
\hline $\begin{array}{l}\text { Caregivers must have professional } \\
\text { training }\end{array}$ & $\begin{array}{l}\text { The New Straits } \\
\text { Times, } 2019\end{array}$ & $\begin{array}{l}\text { The recent report of an older person being } \\
\text { mistreated at an elderly care facility in Seremban is } \\
\text { shocking. The owner of the home has admitted that } \\
\text { the staff has no professional training. This is the } \\
\text { problem faced by most care homes }\end{array}$ \\
\hline $\begin{array}{l}\text { Penang cops 'rescue' elderly } \\
\text { woman allegedly abused by her } \\
\text { children }\end{array}$ & $\begin{array}{l}\text { The New Straits } \\
\text { Times, } 2019\end{array}$ & $\begin{array}{l}\text { A 64-year-old woman, believed to be a victim of } \\
\text { physical abuse, was 'rescued' by the Penang police } \\
\text { yesterday. She had injuries on her head and body, } \\
\text { including old fractures. }\end{array}$ \\
\hline $\begin{array}{l}\text { Man jailed two months for } \\
\text { punching elderly mum in } \\
\text { Brickfields }\end{array}$ & $\begin{array}{l}\text { The New Straits } \\
\text { Times, } 2019\end{array}$ & $\begin{array}{l}\text { An unemployed man was sentenced to two months' } \\
\text { jail by the Magistrate's Court here today for } \\
\text { punching his mother on the eye }\end{array}$ \\
\hline $\begin{array}{l}\text { Elder abuse: A subject many don't } \\
\text { want to talk about }\end{array}$ & $\begin{array}{l}\text { The Star Online, } \\
2016\end{array}$ & $\begin{array}{l}\text { Elder abuse is a growing problem in Malaysia's } \\
\text { fast-aging society, but it is a crime that is grossly } \\
\text { under-reported. Just like domestic violence, most } \\
\text { view it as a "family matter" that is best dealt with in } \\
\text { the family }\end{array}$ \\
\hline
\end{tabular}

As can be seen from the above table, the prevalence of elderly abuse and neglect in Malaysia is increasing annually. Therefore, this paper provides evidence of elderly care and welfare from a different angle. It is also important to note that there are elements of human rights involved, no matter what ages a person is. Another essential element from the media reports from Table 1 indicated the frequency of elderly abuse in a single year, but the location of the misconduct occurred in both the urban and rural areas.

\subsection{Elder Abuse Reporting}

From the literature surveyed, including those in the mass media such as the mainstream newspapers in Malaysia, the reporting of elder abuse requires proper standard operating procedures (SOP). However, who or what government agency should be in charge of this hidden social phenomenon? In many cases, elder abuse reporting was done by caring neighbors (Abdi et al., 2019). However, the vast majority of elder abuse victims remain hidden and unreported from formal institutional response systems (Burnes, Acierno, \& HernandezTejada, 2019; Dow et al., 2019). Help-seeking and reporting of elder abuse by a family member are limited. Hence there is a need to promote more significant elder abuse reporting systems through awareness campaigns and other such promotions. Changes in the legislation are another factor that needs immediate attention, as suggested by Carey, Hodges, and Webb (2018). No doubt, such legislations on disclosing elder abuse to the right authorities may take some time (Dow et al., 2019). Another facet on reporting that should be considered is the victims themselves. If the perpetrator is their offspring, the reluctance to disclose the abuse is the main impediment (ibid). The parental bond is the barrier that prevents the victims from speaking out or asking for help. This situation is common among Asian families as the shame and stigma surrounding the reporting of kin as the perpetrator of abuse is better left undisclosed (ibid). Nonetheless, as recommended by Dow et al. (2019), older people need to be supported to restrict continuous abuse. Hence the change masters need to recognize the unique characteristics in drafting the policy and services in elder abuse reporting.

\subsection{Methodology}

The research project was guided by the qualitative method through in-depth interviews of respondents in a district of Kuala Selangor, Selangor, Malaysia. Residents in the Kpg. Bukit Kapar area was identified through a judgmental sampling technique. These residents have persons above the age of 60 living in the same household. The older persons could be parents or relatives of the homeowners. The sample size was 20 respondents. From the literature reviewed, the qualitative method is apt for this study as the research objectives sought perspectives on elderly care of the local population. Akerlind et al. (2019), pointed out that qualitative research is useful in gaining rich insights of culture-based information about the values, opinions, behaviors, and social contexts of a specific community. 
Nevertheless, the interviews were guided by a semi-structured protocol administered by a research assistant. The guideline consisted of 14 questions that were pre-tested before actual administration. Interviews were necessary for this study to gain rich, in-depth data (Akerlind, Martin, \& Gustafsson, 2019). Repeated visits ensured the consistency of the recorded responses. From the 20 identified, the interview stopped at the $10^{\text {th }}$ respondent as the same responses were recorded for respondents eight and nine, hence achieving data saturation. This technique was supported by Hennink, Kaiser, and Weber (2019) and Bowen (2008). Data collection for this study took two years to complete, as pre-testing, concurrent analyses, and repeated interviews required more time. Also, proper clearance from the university's ethics committee was acquired before the interview sessions

\subsection{Findings}

The findings from the qualitative inquire of ten respondents were profiled, as shown in Table 2. On the contrary, those sent to the oldfolks home have shown mixed perceptions. Thus, the objective of this paper is to provide evidence of elderly welfare using qualitative and descriptive analysis. The reasons for the elderly home caring were because of religion, tradition, and culture.

Table 2. Respondents' Profiles

\begin{tabular}{llll}
\hline Variable & & Frequency & Percentage \\
\hline Gender & Male & 4 & 40 \\
\multirow{4}{*}{ Age } & Female & 6 & 60 \\
& $31-40$ & 4 & 40 \\
\multirow{2}{*}{ Household income } & $41-50$ & 5 & 50 \\
& Above 51 & 1 & 10 \\
& Above RM4501 & 2 & 20 \\
& Between RM3501-4000 & 8 & 80 \\
& & &
\end{tabular}

The above findings are from ten respondents who work in the public sector and have elderly parents. Female respondents (60\%) were more willing to be interviewed on the matter, where 50\% were between $41-50$ years. For the household income, $80 \%$ earned between RM350-4000 per month. On question one about the time spent with their elderly parents, all of them reported weekly meetings at home. This indicates that the parents either live with the respondents or were empty-nesters in their abode. On the hours spent communicating with their parents, the responses vary from one individual to another. In the case of Respondent 2 , the parents live in a rural village, thus limiting face-to-face meetings.

Similarly, Respondent 10 noted that they only meet during festivities. For the respondents whose parents live with them, they talk on an average of two hours per day. For question two on who takes care of the elderly parents, seven of the respondents reported that family members (siblings or spouses) take charge of the elderly parents' welfare. The respondents were also posed a question of whether the elderly parents are willing to be put in a care facility. Only one respondent is agreeable to this, while the remaining nine respondents negate the idea because of limited funds. Question four was on parental neglect, of which a consensus was reached. All the respondents agreed that they would not neglect their parents. The respondents were asked their views on elderly abuse, such as physically harming the parents. Respondent 2 would only use force as a last resort after all persuasions have fallen on deaf ears.

On the contrary, the respondents were steadfast in their religious beliefs that verbal abuse is a sin. Hence elderly parents must be treated with tender, loving care. For the last question, the respondents were queried if the respondents' children on elderly care (of their grandparents). All the respondents agreed that they should show good examples of care and respect as one day, they too will be in the elderly category. The next section will further discuss the findings.

\subsection{Discussions}

The findings revealed that Malaysians are still conservative in caring for their elderly parents. Much of this is because of religion, culture, and tradition. The family values remain internalized in the younger generation even though there have been reports of parental abuse. Also, leadership, by example, is essential for the families to ensure that the next generation does not neglect or abuse the elderly. It has to be ingrained in the young that elderly care and welfare will have positive benefits to the caregivers. Policymakers and change masters do have to put in place the elderly abuse reporting guidelines or procedures.

The findings also revealed that the number of families sending their elderly relatives for geriatric care at private centers had been mixed depending on the financial resources. Sons and daughters with their own families and career have evidenced the need for sending their parents to elderly welfare centers because of time constraints and the inability to provide adequate, professional geriatric care. Policymakers should provide support on temporary care for the elderly when the children go to work but only for those who do not require excessive medical interventions. Fortunately for the elderly, there is a World Elder Abuse Awareness Day (WEAAD). This is the awareness campaign that would assist with limiting elderly abuse in Malaysia.

The research project is part of sociology with the scope of families. Family violence is hidden, subjectively defined, and difficult to measure (Barnett, Miller-Perrin, \& Perrin, 2005). Put within the context of culture, tradition, and religion, clarity issues emerge. The delineation of family values between those in the western countries to that in the Asian region differ. How a family regards one's parents is also a contention. In the case of parental or elder abuse, it is impossible to estimate precisely how frequently it occurs. Respondents may not want to divulge family secrets. However, this study takes some strength in closing the gap on elder abuse. Abuse in any form should not be condoned as the country's socio-economy may be affected if unhappy communities abound. 


\subsection{Conclusion and Recommendations}

The study provides invaluable insights into elderly welfare in Malaysia. Even though there have been instances of neglect among the elderly, the care is given by immediate family members has proven to be the core value in Asian families. Modern families may provide excuses on the need to focus on their young, nuclear families. However, the continuation of a long-held tradition, culture, and religious upbringing has shown otherwise. Hence, it is recommended that relevant stakeholders and policymakers ensure that more attention is given to the elderly. In cases of abuse, there has to be a proper reporting policy. Also, the elderly can continue to contribute to society if they are still capable of doing so. In the research aspect, it is recommended that similar studies be undertaken with a broader scope.

\section{Acknowledgments}

The research project was conducted under the provision of a grant, the Fundamental Research Grant Scheme (FRGS 053/2017), awarded by the Ministry of Education, Malaysia. The researchers would also like to thank Universiti Teknologi MARA, Cawangan Selangor, Puncak Alam Campus for the support and other assistance.

\section{References}

Abdi, A., Tarjoman, A., \& Borji, M. (2019). Prevalence of elder abuse in Iran: a Systematic review and meta-analysis. Asian Journal of Psychiatry, 39, 120-127. doi:10.1016/j.ajp.2018.12.005

ADB. (2017). Population and Aging in Asia: The Growing Elderly Population. Retrieved from https://www.adb.org/features/asia-s-growing-elderly-population-adb-s-take

Akerlind, C., Martin, L., \& Gustafsson, C. (2019). Care managers' perceptions of eHomecare: a qualitative interview study. European Journal of Social Work, 22(4), 634646. doi:10.1080/13691457.2017.1366893

Barnett, O., Miller-Perrin, C. L., \& Perrin, R. D. (2005). Family Violence Across the Lifespan: An Introduction (2nd ed.). Thousand Oaks, CA, USA: Sage.

Bowen, G. A. (2008). Naturalistic inquiry and the saturation concept: a research note. Qualitative Research, 8(1), 137-152. doi:10.1177/1468794107085301

Burnes, D., Acierno, R., \& Hernandez-Tejada, M. (2019). Help-Seeking Among Victims of Elder Abuse: Findings From the National Elder Mistreatment Study. The journals of gerontology. Series B, Psychological sciences and social sciences, 74(5), 891-896. doi:10.1093/geronb/gby122

Carey, C., Hodges, J., \& Webb, J. K. (2018). Changes in state legislation and the impacts on elder financial fraud and exploitation. Journal of Elder Abuse and Neglect, 30(4), 309-319. doi:10.1080/08946566.2018.1479670

Cheng, S. T., \& Cheng, S. T. (2015). Demographic and family trends in Asia. In Successful Aging: Asian Perspectives (pp. 21-32).

Daskalopoulou, C., Koukounari, A., Wu, Y. T., Terrera, G. M., Caballero, F. F., de la Fuente, J., . . . Prina, M. (2019). Healthy ageing trajectories and lifestyle behaviour: the Mexican Health and Aging Study. Scientific Reports, 9(1). doi:10.1038/s41598-019-47238-w

Davies, M. (1993). Recognizing Abuse: An assessment tool for nurses. In P. Decalmer \& F. Glendenning (Eds.), The Mis-treatment of Elderly People (pp. 102-116). London, UK: Sage.

Decalmer, P., \& Glendenning, F. (1993). The Mistreatment of Elderly People. London, UK: Sage.

Dickerson, K. L., Lindner, S., Scurich, N., \& Quas, J. A. (2017). When Is Neglect, Neglect?: It Depends on Who You Ask. Child Maltreatment, 22(3), 256-264. doi:10.1177/1077559517709558

Dow, B., Gahan, L., Gaffy, E., Joosten, M., Vrantsidis, F., \& Jarred, M. (2019). Barriers to Disclosing Elder Abuse and Taking Action in Australia. Journal of Family Violence. doi:10.1007/s10896-019-00084-w

Friedman, L. S., Avila, S., Rizvi, T., Partida, R., \& Friedman, D. (2017). Physical Abuse of Elderly Adults: Victim Characteristics and Determinants of Revictimization. Journal of the American Geriatrics Society, 65(7), 1420-1426. doi:10.1111/jgs.14794

Helton, J. J., Boutwell, B. B., \& DiBernardo, M. (2017). The relative safety of paternal, maternal, and traditional foster care placements. Child Abuse and Neglect, 70, 1 10. doi:10.1016/j.chiabu.2017.05.006

Hennink, M. M., Kaiser, B. N., \& Weber, M. B. (2019). What Influences Saturation? Estimating Sample Sizes in Focus Group Research. Qualitative Health Research, 29(10), 1483-1496. doi:10.1177/1049732318821692

Mafauzy, M. (2000). The problems and challenges of the aging population of Malaysia. The Malaysian Journal of Medical Sciences, 7(1), 1-3.

Organization, W. H. (2018). Aging and health. Retrieved from https://www.who.int/news-room/fact-sheets/detail/ageing-and-health

Statistics-Malaysia, D. o. (2019). Current Population Estimates, Malaysia, 2018-2019. Retrieved from https://www.dosm.gov.my/v1/index.php?r=column/cthemeByCat\&cat=155\&bul_id=aWJZRkJ4UEdKcUZpT2tVT090Snpydz09\&menu_id=L0pheU43NWJwRWVSZkIWdz Q4TIhUUT09 